\title{
A comparison of prey richness estimates for Weddell seals using diving profiles and image data
}

\author{
Yoshihisa Mori ${ }^{1, *}$, Yuuki Watanabe ${ }^{2}$, Yoko Mitani ${ }^{3,5}$, Katsufumi Sato ${ }^{3,6}$, \\ Michael F. Cameron ${ }^{4,7}$, Yasuhiko Naito ${ }^{3}$ \\ ${ }^{1}$ Department of Animal Sciences, Teikyo University of Science and Technology, 2525 Yatsuzawa, Uenohara, \\ Yamanashi 409-0193, Japan \\ ${ }^{2}$ The Ocean Research Institute, The University of Tokyo, 1-15-1 Minamidai, Nakano, Tokyo 164-8639, Japan \\ ${ }^{3}$ National Institute of Polar Research, 1-9-10 Kaga, Itabashi, Tokyo 173-8515, Japan \\ ${ }^{4}$ Department of Ecology, Evolution, and Behavior, University of Minnesota, 100 Ecology Building, 1987 Upper Buford Circle, \\ St. Paul, Minnesota 55108, USA \\ ${ }^{5}$ Present address: Texas A \& M University at Galveston, 5007 Avenue U, Galveston, Texas 77551, USA \\ ${ }^{6}$ Present address: International Coastal Research Center, The Ocean Research Institute, The University of Tokyo, \\ 2-106-1 Akahama, Otsuchi, Iwate 028-1102 Japan
}

${ }^{7}$ Present address: National Marine Mammal Laboratory, NOAA 7600 Sand Point Way NE, Seattle, Washington 98115, USA

\begin{abstract}
Diving animals such as seabirds and marine mammals are top predators foraging under water, and play an important role in the marine ecosystems through foraging behavior. Recently developed animal-borne digital video or still cameras have made it possible to directly observe and estimate the prey richness of a foraging patch with simultaneously recorded diving profiles. Optimal foraging theory suggests that patch residence time should be affected both by the time it takes to travel to a prey patch and the richness of the patch. Therefore, diving profiles obtained by animalborne depth and time instruments may be used to calculate a relative index of the richness of a prey patch used by diving animals in the water column. We tested this hypothesis by comparing the indices of prey richness estimated from both dive profiles and image data using adult female Weddell seals Leptonychotes weddellii at breeding colonies in Antarctica. There was a positive correlation between these 2 values, indicating that dive profiles can be used effectively to calculate a relative index of prey richness at a prey patch used by diving animals.
\end{abstract}

KEY WORDS: Foraging · Patch residence time · Prey patch quality · Diving • Optimal model

\section{INTRODUCTION}

All predators have to make choices about where to feed, what to feed on and how much to feed. In turn, these decisions affect the distribution and abundance of prey species in ecosystems (Townsend et al. 2000). To fully understand the foraging ecology of predators, we need information about foraging behavior and the conditions under which predators forage. In the marine environment, diving animals such as seabirds and marine mammals are top-level predators, and play an important role in the ecosystems through foraging
(Croll et al. 1998). Unfortunately, these diving animals forage underwater, where we are rarely able to make direct observations. However, recent developments in animal-borne recording devices (i.e. data-loggers) have made it possible to simultaneously obtain diving and environmental data during foraging. For example, in addition to the time-depth profiles of dives, multichannel data-loggers can record the physical (e.g. temperature) and/or chemical (e.g. salinity) measurements of the environment (e.g. Hooker \& Boyd 2003). Dataloggers equipped with cameras can record individual capture and feeding events, as well as the prey type, 
on video (Davis et al. 1992, 1999, Ponganis et al. 2000, Fuiman et al. 2002) or from still pictures (Hooker et al. 2002, Sato et al. 2002, Watanabe et al. 2003). Using pictures taken during the foraging dives of Weddell seals Leptonychotes weddellii, Watanabe et al. (2003) calculated a 'prey index' based on the numbers and size of prey-like objects. Watanabe et al. (2003) used this index to quantitatively evaluate the prey richness encountered by animals during foraging dives, and discussed the seals' diving behavior in relation to the distribution and density of prey.

Prior to these types of analyses, the prey richness experienced during a foraging event had to be inferred from dive profiles and associated parameters (e.g. dive time, traveling time, bottom time and surface time; Thompson \& Fedak 2001, Mori et al. 2002, Mori \& Boyd 2004). For optimally foraging, diving animals, the time spent in a prey field (i.e. patch residence time) should be related to the time it takes to travel between the surface and a prey patch, and to the prey richness of the patch (e.g. Stephens \& Krebs 1986). Therefore, diving profiles should reflect not only the depth of a prey patch, but also the richness of the patch. Based on this idea, Mori et al. (2002) developed an index of prey richness at a foraging patch (the index of patch quality, IPQ). Mori \& Boyd (2004) calculated the IPQ from the diving profiles of Antarctic fur seals Arctocephalus gazella, and estimated the prey richness of foraging patches that the fur seals used. The annual means of these IPQs were positively correlated with the mean krill density of the foraging areas, as measured by hydro-acoustic surveys, suggesting that diving profiles can be used as an index of overall prey richness. However, to directly compare the IPQ with prey richness for each dive requires both dive profiles and prey richness measurements to be collected simultaneously. We used the prey richness (i.e. prey index) and the dive profile data reported by Watanabe et al. (2003) to test the usefulness of the IPQ in estimating the prey richness of a foraging patch at the level of an individual dive.

\section{MATERIALS AND METHODS}

Data collection. The dataset used in the present study has been previously reported by Watanabe et al. (2003) and Mitani et al. (2004). Dive data were collected from lactating female Weddell seals with live pups between 10 November and 12 December 2000, at Big Razorback Island $\left(77.68^{\circ} \mathrm{S}, 166.50^{\circ} \mathrm{E}\right)$ and Turks Head $\left(77.67^{\circ} \mathrm{S}, 166.78^{\circ} \mathrm{E}\right)$, in the region of McMurdo Sound, Antarctica. Both breeding sites are covered with fast ice during the breeding season. At Big Razorback Island, these cracks are oriented close and parallel to the coastline of the island. As such, to reach deep water quickly, seals must swim at a relatively shallow angle (approx. $30^{\circ}$ ) and follow the slope of the island. In contrast, the primary crack at Turks Head is perpendicular to the coastline and over deep water. Additionally, the underwater slope is much steeper than at Big Razorback Island, and seals along this crack may dive steeply to reach deeper depths.

Digital cameras (DSL-1000DV cameras; Little Leonardo) were used to collect dive data and still images while animals were underwater. The DSL weighed $3.4 \mathrm{~kg}$ in air (approx. $1 \%$ of a seal's body mass) and $1.6 \mathrm{~kg}$ in water, and comprised 2 cylindrical housings, each $230 \mathrm{~mm}$ in length and $52 \mathrm{~mm}$ in diameter. One housing contained the color digital camera (minimum illumination 8 lux; angle of view $45^{\circ}$; effective resolution $510 \times 492$ pixels; automatic white balance). The other housing contained a flash (Guide Number 32). The camera was programmed to take digital images every $30 \mathrm{~s}$ when the seal was diving deeper than $5 \mathrm{~m}$. Depth data were recorded every $1 \mathrm{~s}$ at a resolution of $1 \mathrm{~m}$. The DSLs were attached to 4 seals at each site for 1 to $2 \mathrm{~d}$. For further details of the field work and experiment, see Watanabe et al. (2003) and Mitani et al. (2004). See also Sato et al. (2003), Watanabe et al. (2003) and Mitani et al. (2004) for detailed reports on the diving behavior of Weddell seal populations breeding at these sites.

Data analysis and estimates of prey index from image data. All dives $>50 \mathrm{~m} \mathrm{(42}$ and 55 dives for each site) were used in the analysis, because such depths were likely correlated with foraging (Sato et al. 2002). Each dive was subdivided into a descent phase (from the beginning of a dive to the time of the first ascent while deeper than $50 \mathrm{~m}$ ), an ascent phase (from the depth of the last descent while deeper than $50 \mathrm{~m}$ to the end of dive) and a bottom phase (the time between the end of descent and beginning of ascent). Surface time was defined as the time between dives. Using the log-survivorship analysis (Gentry \& Kooyman 1986), those 42 and 55 dives were split into 21 and 25 dive bouts for each site, respectively; if the surface time between 2 successive dives was longer than $15 \mathrm{~min}$, these dives were considered to be in different dive bouts.

The prey index, developed and reported by Watanabe et al. (2003), was calculated from the number and size of prey-like objects on the recorded still images:

$$
\text { Prey index }=\left(A_{0} / A_{\mathrm{a}}\right) \times\left(n \times A_{\mathrm{w}} / A_{\mathrm{a}}\right)
$$

where $A_{0}$ is the total area occupied by objects, $A_{\mathrm{a}}$ is the available area excluding the area hidden by the datalogger, $n$ is the number of objects and $A_{\mathrm{w}}$ is the whole area of the image. The mean prey index was the average of the non-zero prey index values during the bottom phase in the present study. 
Extracting prey-like objects from images, Watanabe et al. (2003) used the difference in brightness between the objects and background (see Watanabe et al. 2003 for details). We assumed that those prey-like objects were prey, potentially Pleuragramma antarcticum, which is considered to be the major prey of the local Weddell seal population in McMurdo Sound (Watanabe et al. 2003). Thus, the prey index is assumed to be related with the density of $P$. antarcticum, but it should be noted that the large ( $>1 \mathrm{~m})$, less common benthic toothfish, e.g. Dissosichus mawsoni, is also a preferred prey item (Davis et al. 2004).

Estimates of prey richness from diving profiles. The methods for estimating prey richness solely from diving profiles are described in Mori et al. (2002) and Mori \& Boyd (2004). In short, Thompson \& Fedak (2001) and Mori et al. (2002) hypothesized that variations in traveling time are caused by variations in patch depth and that variations in bottom time, for a given traveling time, are caused by variations in patch quality, all of which is assessed by the IPQ; see Appendix 1 for details.

Calculating the IPQ requires the relationship between dive time and surface time associated with the dive time (Mori et al. 2002). We used the regression function of dive time, $u$, to surface time, $s$, for this relationship. We used dives with a pre-dive surface time shorter than $15 \mathrm{~min}$. The regression functions were $u=$ $21.0 \times[1-\exp (-0.35 \times s)]$ for Big Razorback Island and $u=20.3 \times[1-\exp (-0.48 \times s)]$ for Turks Head (Fig. 1) We calculated the IPQ for each dive using the inverse functions of these regression functions.

It should be noted that we could not calculate the IPQs for dives longer than $20 \mathrm{~min}$, because the regression functions indicated that the dive time could not be longer than 21.0 or $20.3 \mathrm{~min}$ in the present study. It has been estimated that the aerobic dive limit (ADL) for Weddell seals was 20 to 25 min (Kooyman et al. 1980, Kooyman 1989, Boyd 1997). Thus, most dives for which the IPQ was estimated were regarded as aerobic dives. Additionally, 28 of the $42(66.7 \%)$ dives at Big Razorback and 36 of the $55(65.5 \%)$ dives at Turks Head were shorter than 20 min. Only 3 dives at each colony were longer than $25 \mathrm{~min}$. For statistical tests, we pooled data from the different individuals for each site because of the small sample sizes obtained from each individual.

\section{RESULTS}

The IPQ was positively correlated with the maximum prey index estimated from the image data collected during the bottom phase for seals breeding at both Big Razorback Island (BR) and Turks Head (TH) (Spear-

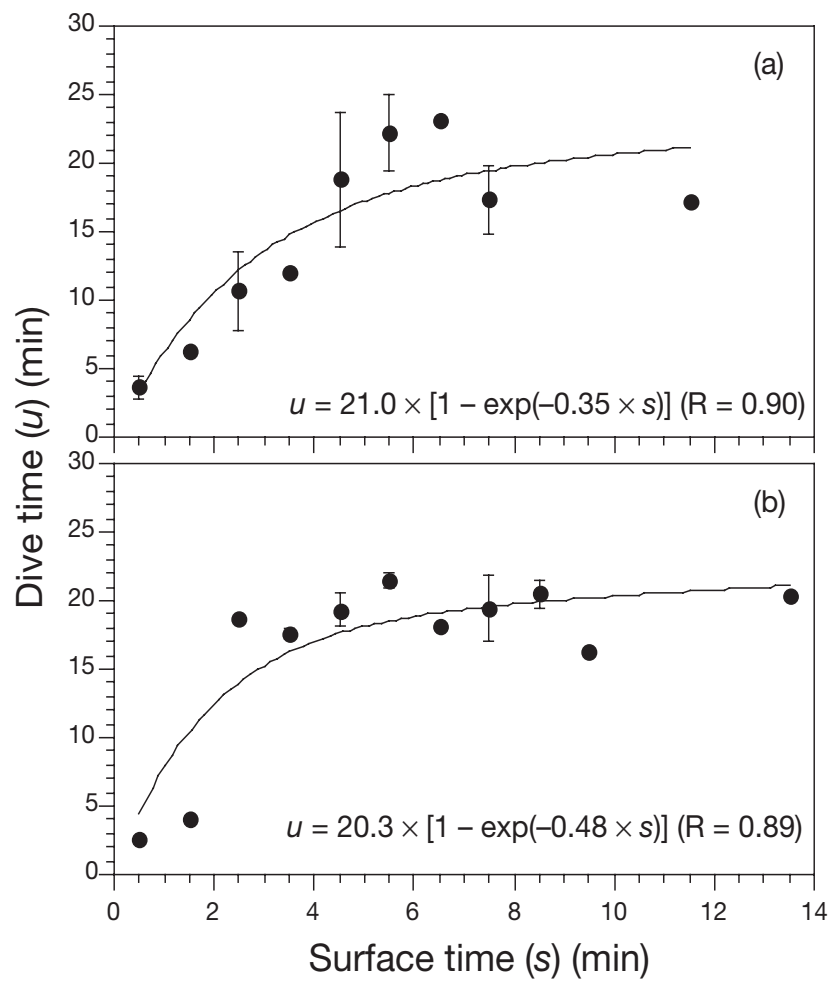

Fig. 1. Leptonychotes weddellii. Dive time and surface time associated with the dive time for Weddell seals at (a) Big Razorback Island and (b) Turks Head. Mean dive times $( \pm \mathrm{SE})$ for surface times of every $60 \mathrm{~s}$ are shown. Regression lines are shown with equations and R-values

man's rank correlation, $\mathrm{r}_{\mathrm{s}}=0.68$, sample size, $\mathrm{n}=28$, $\mathrm{p}<0.001$ and $\mathrm{r}_{\mathrm{s}}=0.42, \mathrm{n}=36, \mathrm{p}<0.05$, for BR and $\mathrm{TH}$, respectively) (Fig. 2). However, the mean prey index was only correlated with the IPQ for seals at BR $\left(\mathrm{r}_{\mathrm{s}}=\right.$ $0.64, \mathrm{n}=28, \mathrm{p}<0.01$ and $\mathrm{r}_{\mathrm{s}}=0.25, \mathrm{n}=36, \mathrm{p}=0.14$, for $\mathrm{BR}$ and $\mathrm{TH}$, respectively) (Fig. 3). The IPQ was also positively correlated with the mean maximum prey index during a bout $\left(\mathrm{r}_{\mathrm{s}}=0.54, \mathrm{n}=21, \mathrm{p}<0.05\right.$ and $\mathrm{r}_{\mathrm{s}}=$ $0.51, \mathrm{n}=25, \mathrm{p}<0.05$, for $\mathrm{BR}$ and $\mathrm{TH}$, respectively). Similarly, the mean prey index during a bout was correlated with the IPQ for seals at both locations $\left(\mathrm{r}_{\mathrm{s}}=\right.$ $0.50, \mathrm{n}=21, \mathrm{p}<0.05$ and $\mathrm{r}_{\mathrm{s}}=0.35, \mathrm{n}=25, \mathrm{p}=0.08$, for $\mathrm{BR}$ and $\mathrm{TH}$, respectively). These findings show the overall tendency for prey richness, as estimated from dive profiles, to be positively correlated with the prey richness index calculated using images. In addition, this correlation tended to be greater for BR than for TH.

The median of the maximum prey index for dives longer than 20 min was significantly larger than that for dives shorter than $20 \mathrm{~min}$, while the median of the mean prey index did not show this tendency (Table 1). This suggests that longer (i.e. anaerobic) dives indicate a relatively high maximum prey richness. 


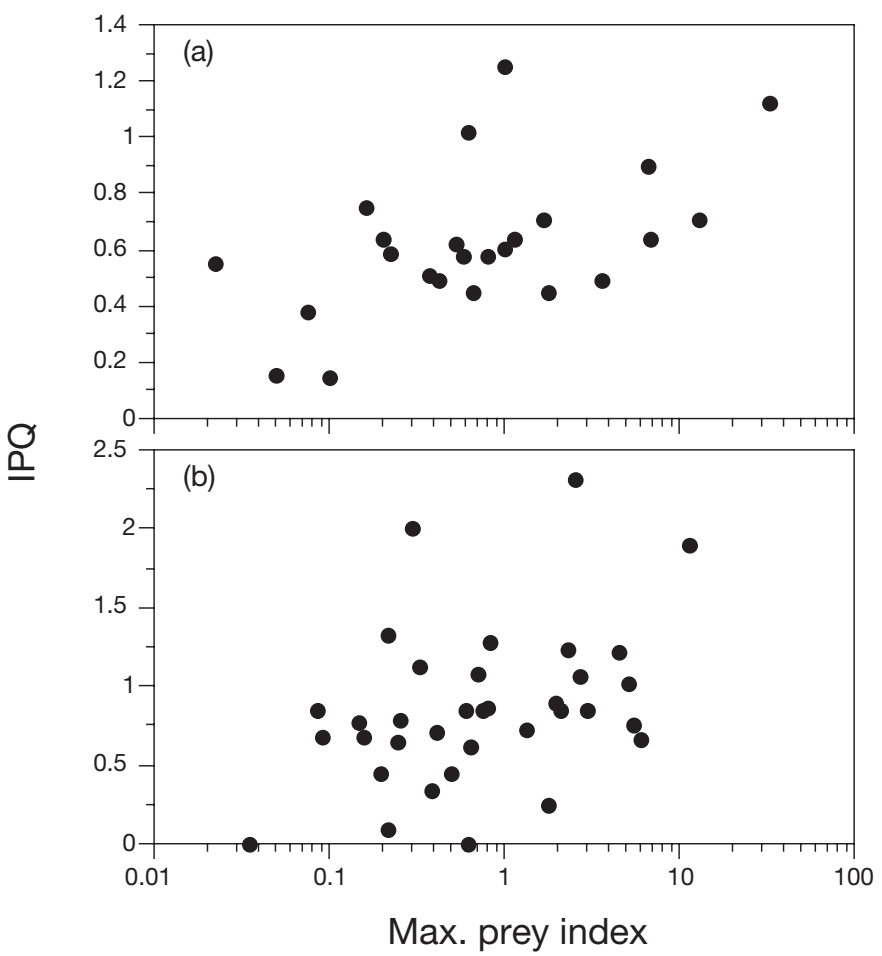

Fig. 2. Leptonychotes weddellii. Maximum prey index during bottom time and index of patch quality (IPQ) for (a) Big Razorback Island and (b) Turks Head. See 'Results' for Spearman's rank correlation test

\section{DISCUSSION}

Our findings support the prediction that dive profiles do indeed reflect the relative richness of prey patches encountered during a dive. They also suggest that dive profiles can be used as reliable indices of the relative prey richness of a prey patch used by diving animals. As dive records have been collected by many researchers over the last few decades, we expect that reanalyzing these accumulated data in relation to prey richness will help our understanding of the foraging

Table 1. Statistics of prey index during a bottom time in relation to dive time. Statistical difference was tested by Mann-Whitney $U$-test. Sample sizes are in parentheses

\begin{tabular}{|c|c|c|c|c|c|c|}
\hline \multirow[t]{2}{*}{ Dive time } & \multirow{2}{*}{\multicolumn{2}{|c|}{$\begin{array}{l}\leq 20 \min \\
\text { Median }\end{array}$}} & \multirow{2}{*}{\multicolumn{2}{|c|}{$\begin{array}{l}>20 \min \\
\text { Median }\end{array}$}} & \multicolumn{2}{|c|}{ Statistical difference } \\
\hline & & & & & $U$ & $\mathrm{p}$ \\
\hline \multicolumn{7}{|l|}{ Maximum prey index } \\
\hline Big Razorback Island & 0.560 & (28) & 1.310 & (14) & 202.0 & 0.013 \\
\hline Turks Head & 0.627 & (36) & 1.536 & (19) & 127.0 & 0.065 \\
\hline \multicolumn{7}{|l|}{ Mean prey index } \\
\hline Big Razorback Island & 0.129 & (28) & 0.123 & (14) & 143.5 & 0.16 \\
\hline Turks Head & 0.161 & (36) & 0.200 & (19) & 267.0 & 0.18 \\
\hline
\end{tabular}

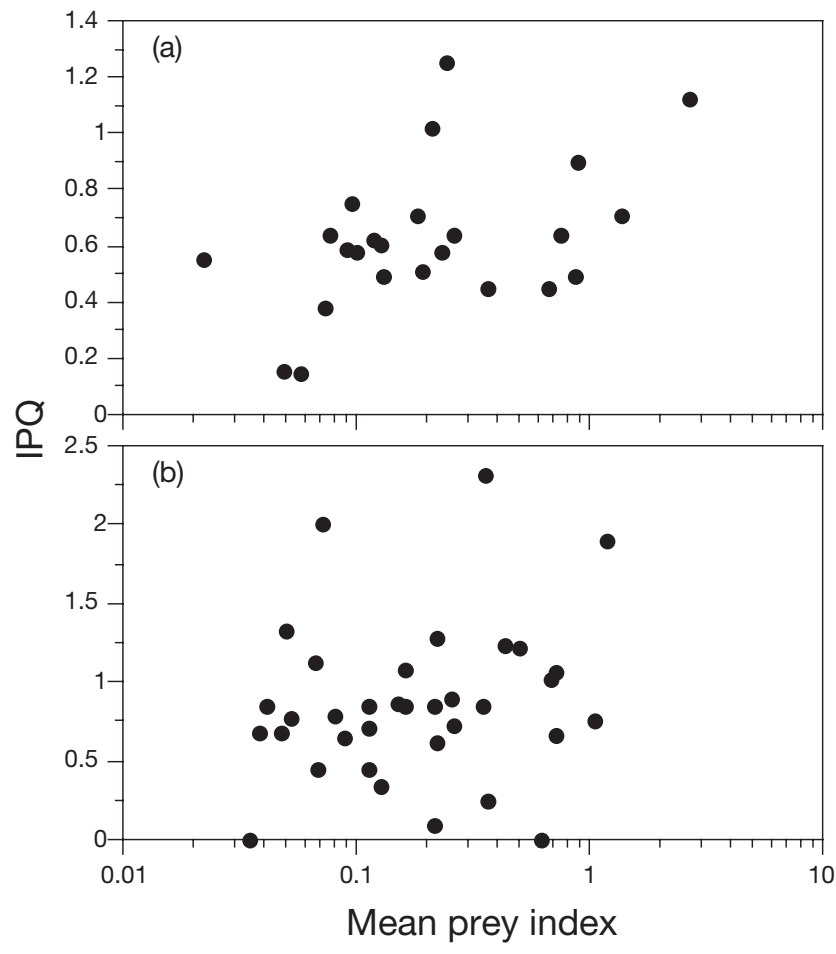

Fig. 3. Leptonychotes weddellii. Mean prey index during bottom time and index of patch quality (IPQ) for (a) Big Razorback Island and (b) Turks Head. See 'Results' for Spearman's rank correlation test

ecology of top predators in marine ecosystems. For example, using the IPQ, Mori \& Boyd (2004) reanalyzed $>200000$ dives performed by Antarctic fur seals and revealed their foraging strategy and functional responses to varying prey abundance.

Most theories concerning optimal patch residence time and optimal foraging theory have been tested, with most of the predictions regarding patch residence time in response to prey abundance being qualitatively supported (see Stephens \& Krebs 1986, Nonacs 2001, for review). This suggests that patch residence time, with a correction for traveling time, which can also affect patch residence time, can be used as an index of relative prey richness of the patch. Our results provide evidence to support this prediction in a diving animal.

The prey index calculated from image data was greater for dives longer than 20 min (Table 1), indicating that the animal chose to remain in prey patches of a high density for longer periods of time. These long dives likely exceeded the aerobic dive limit of Weddell seals (Kooyman et al. 1980, Kooyman 1989, Boyd 1997). 
Theoretical models predict that anaerobic diving should be made in high-quality prey patches (Ydenberg \& Clark 1989, Mori 1998). Our finding of the greater prey index for dives longer than 20 min supports these predictions.

We used the maximum and mean prey indices during bottom time to be representative of the prey richness of the prey patch used by seals. Both the maximum prey index and the mean prey index during the bottom phase were positively correlated with each other (Spearman's rank correlation, $\mathrm{r}_{\mathrm{s}}=0.96, \mathrm{n}=28$, $\mathrm{p}<0.0001$ and $\mathrm{r}_{\mathrm{s}}=0.92, \mathrm{n}=36, \mathrm{p}<0.0001$, for BR and $\mathrm{TH}$, respectively), but the ranges of these 2 variables were markedly different; the ranges of the maximum prey index were 0.022 to 32.607 and 0.035 to 49.276 for $\mathrm{BR}$ and $\mathrm{TH}$, respectively, while those of the mean prey index were 0.022 to 4.356 and 0.023 to 2.435 for BR and TH, respectively. It appears that the seals adjusted their diving behavior in relation to the maximum prey index more than to the mean prey index, because the IPQ was always correlated positively with the maximum prey index, but not always with the mean prey index. Mitani et al. (2004) have analyzed the trajectories of foraging dives in Weddell seals, and found that, in most cases, the furthest point of a trajectory has the greatest prey index. This suggests that seals begin to return to the surface at the point where the prey density is the highest in the prey patch. This is consistent with our finding that the seals adjusted their diving behavior in relation to the maximum prey index rather than the mean prey index. However, the image sampling interval of $30 \mathrm{~s}$ would be too long to discuss the possible cues for prey richness by which seals may adjust their foraging behavior.

The coefficient of rank correlation $\left(\mathrm{r}_{\mathrm{s}}\right)$ between the 2 indices was always greater for BR than $\mathrm{TH}$. This suggests that the diving profiles more accurately reflected the richness of prey patches at BR than $\mathrm{TH}$ and that seals at BR were more sensitive to changes in prey richness and adjusted their dive profiles accordingly. We suggest that these differences may be due to the different foraging pressures caused by the topography of the 2 colonies. Both breeding sites were covered with sea ice, and Weddell seals used naturally occurring cracks or holes on the surface of the ice to enter the water for foraging. The seals appeared to use the same cracks to enter and exit the water. Sato et al. (2003) reported that seals at TH swim vertically to reach the bottom, but those at BR were restricted by the local bathymetry and were required to follow the slope of the island and to swim at a more shallow angle to reach deeper waters for foraging. In addition, seals at BR were more likely to adopt the energetically costly stroke-and-glide technique, in comparison with the prolonged gliding adopted by seals at TH (Sato et al. 2003). The increased time and energy (or oxygen) spent in transit at BR suggested that the seals at BR would not be able to afford the time and oxygen for foraging in comparison with those at TH. One would expect that seals that experience a greater cost while feeding would benefit from a higher sensitivity to prey richness that would allow them to better allocate their time spent foraging.

To estimate prey richness from diving profiles, we assumed that optimally foraging seals maximize net energy intake during a dive cycle. Therefore, the goodness-of-fit of estimates of the observed data depends on how likely this assumption is. Stage in a breeding season, body condition and existence of predators could affect time allocation during a dive cycle. Our method did not include these concerns as factors, but for the purpose of calculating relative estimates of prey richness or comparing such estimates across similar conditions, our method is useful.

We could not calculate the IPQ for dives longer than 20 min in the present study. Calculating the IPQ for long dives would require an alternate dive timesurface time function. Unfortunately, incorporating anaerobic metabolisms into theoretical models for a dive cycle is difficult and imprecise (Carbone \& Houston 1996, Mori 1998, 1999). The functions used in our models were relatively simple. More complex functions would provide better predictions of the prey richness at prey patches used by diving animals, and knowing the exact relationships between dive time, surface time, bottom time and accumulated energy intake would improve our correlations of dive profiles and actual prey richness.

The prey index and the IPQ represent estimates of prey abundance in the present study. We made the assumption that the prey index is potentially related to the density of Pleuragramma antarcticum in a prey patch (Watanabe et al. 2003). Therefore, our approach is useful when Weddell seals forage on this type of prey. It is, however, true that Weddell seals prefer other types of prey, such as the rarer and larger benthic Antarctic toothfish (Davis et al. 2004). To calculate the $I P Q$, we assumed that patch residence time would be long if the prey patch is good. However, when the size of prey is very large, the longer patch residence time would not necessarily be correlated with better foraging conditions at a prey patch, because smaller numbers of larger prey are sufficient in terms of energy intake. Also, capturing digital footage of these prey events would be very difficult with a $30 \mathrm{~s}$ interval. Therefore, it is important to identify the relationship between the diving behavior of animals and the type of prey they take, in order to estimate prey abundance using diving profiles. 
In conclusion, we found that the index of prey richness obtained from diving profiles was positively correlated with the prey richness estimated from image data and that diving profiles are useful for identifying prey patch richness of certain, more abundant species. Furthermore, our findings suggest that a relative measurement of prey patch richness is possible without employing expensive methods such as hydroacoustic surveys by vessels or seal-borne video cameras, in regions where prey species are either few or known. We can expect that analyzing the diving profiles in relation to prey richness would increase our understanding of the foraging ecology of top predators in marine ecosystems.

Acknowledgements. We thank anonymous referees for helpful comments on the manuscript. The experimental protocol was previously approved by the National Marine Fisheries Service, Marine Mammal Protection Agency. This work was supported by the Japanese Society for the Promotion of Science (14405027 and 15255003) and by the National Science Foundation (OPP-9420818).

\section{LITERATURE CITED}

Boyd IL (1997) The behavioural and physiological ecology of diving. Trends Ecol Evol 12:213-217

Carbone C, Houston AI (1996) The allocation of time over the dive cycle: an approach based on aerobic and anaerobic respiration. Anim Behav 51:1247-1255

Croll DA, Tershy BR, Hewitt RP, Demer DA and 8 others (1998) An integrated approach to the foraging ecology of marine birds and mammals. Deep-Sea Res II 45: 1353-1371

Davis RW, Wartzok D, Elsner R, Stone H (1992) A small video attached to a Weddell seal: a new way to observe diving behavior. In: Thomas JA, Kastelein R, Supin AY (eds) Marine mammal sensory systems. Plenum Press, New York, p 631-642

Davis RW, Fuiman LA, Williams TM, Collier SO, Hagey WP, Kanatous SB, Kohhin S, Horning M (1999) Hunting behavior of a marine mammal beneath the Antarctic fast ice. Science 283:993-995

Davis RW, Hagey W, Horning M (2004) Monitoring the behavior and multi-dimensional movements of Weddell seals using an animal-borne video and data recorder. Mem Natl Inst Polar Res (Spec Iss) 58:148-154

Fuiman LA, Davis RW, Williams TM (2002) Behavior of midwater fishes under the Antarctic ice: observation by a predator. Mar Biol 140:815-822

Gentry RL, Kooyman GL (1986) Methods of dive analysis. In: Gentry RL, Kooyman GL (eds) Fur seals: maternal strategies on land and at sea. Princeton University Press, Princeton, NJ, p 28-40
Hooker SK, Boyd IL (2003) Salinity sensors on seals: use of marine predators to carry CTD dataloggers. Deep-Sea Res I 50:927-939

Hooker SK, Boyd IL, Jessopp M, Cox O, Blackwell J, Boveng PL, Bengtson JL (2002) Monitoring the prey-field of marine predators: combining digital imaging with datalogging tags. Mar Mamm Sci 18:680-697

Kooyman GL (1989) Diverse divers: physiology and behavior. Springer-Verlag, Berlin

Kramer DL (1988) The behavioural ecology of air breathing by aquatic animals. Can J Zool 66:89-94

Kooyman GL, Wahrenbrock EA, Castellini MA, Davis RW, Sinnett EE (1980) Aerobic and anaerobic metabolism during voluntary diving in Weddell seals: evidence of preferred pathways from blood chemistry and behaviour. J Comp Physiol 138:335-346

Mitani Y, Watanabe Y, Sato K, Cameron MF, Naito Y (2004) $3 \mathrm{D}$ diving behavior of Weddell seals with respect to prey accessibility and abundance. Mar Ecol Prog Ser 281: $275-281$

Mori Y (1998) The optimal patch use in divers: optimal time budget and the number of dive cycles during bouts. J Theor Biol 190:187-199

Mori Y (1999) The optimal allocation of time and respiratory metabolism over the dive cycle. Behav Ecol 10:155-160

Mori Y, Boyd IL (2004) The behavioral basis for non-linear functional responses and optimum foraging in Antarctic fur seals. Ecology 85:398-410

Mori Y, Takahashi A, Mehlum F, Watanuki Y (2002) An application of optimal diving models to diving behaviour of Brünnich's guillemots. Anim Behav 64:737-743

Nonacs P (2001) State dependent behavior and the marginal value theorem. Behav Ecol 12:71-83

Ponganis PJ, Vandam RP, Marshall G, Knower T, Levenson DH (2000) Sub-ice foraging behavior of emperor penguins. J Exp Biol 203:3275-3278

Sato K, Mitani Y, Cameron MF, Siniff DB, Watanabe Y, Naito $Y$ (2002) Deep foraging dives in relation to the energy depletion of Weddell seal (Leptonychotes weddellii) mothers during lactation. Polar Biol 25:696-702

Sato K, Mitani Y, Cameron MF, Siniff DB, Naito Y (2003) Factors affecting stroking patterns and body angle in diving Weddell seals under natural conditions. J Exp Biol 206: 1461-1470

Stephens DW, Krebs JR (1986) Foraging theory. Princeton University Press, Princeton, NJ

Thompson D, Fedak MA (2001) How long should a dive last? A simple model of foraging decisions by breath-hold divers in patchy environment. Anim Behav 61:287-296

Townsend CR, Harper JL, Begon M (2000) Essentials of ecology. Blackwell Science, Boston, MA

Watanabe Y, Mitani Y, Sato K, Cameron MF, Naito Y (2003) Dive depths of Weddell seals in relation to vertical prey distribution as estimated by image data. Mar Ecol Prog Ser 252:283-288

Ydenberg RC, Clark CW (1989) Aerobiosis and anaerobiosis during diving by western grebes: an optimal foraging approach. J Theor Biol 139:437-449 
Appendix 1. General procedure used to estimate prey richness from diving profiles based on models in Mori et al. (2002) and Mori \& Boyd (2004)

We can obtain the 3 following variables from diving profiles: traveling time, $t$, spent for traveling from the surface to a foraging area at a depth and back to the surface; bottom time, $b$, spent in the foraging area for feeding; and surface time, $s$, spent for recovery or replenishment for diving. Dive time, $u$, which is $t+b$, is supposed to be an increasing but decelerating function of the surface time, $s$ (e.g. Kooyman et al. 1980, Kramer 1988). Thus, it follows that:

$$
u=f(s)
$$

Since the bottom time is considered to be used for foraging in a prey patch (Hooker et al. 2002, Watanabe et al. 2003), the amount of energy intake during a dive cycle, $g$, can be an increasing function of the bottom time, $b$, and prey richness, $x$, at the prey patch and is expressed as:

$$
g=y(b, x)
$$

Then, the energy intake rate during a dive cycle (dive time + surface time), $P$, is:

$$
P=g /(u+s)=y(b, x) /[f(s)+s]
$$

This equation can be transformed, using the reverse function of $u=f(s)$ or $s=f^{-1}(u)$, into:

$$
P=y(b, x) /\left[f^{-1}(u)+u\right]
$$

We can obtain $t$ and $b$ from each diving profile. The function $u=f(s)$ can be estimated by regression of dive time, $u$, to surface time, $s$, using observed data. We do not have exact information on the function of energy intake during a dive cycle, $g$, but we assumed that the rate of energy intake declines throughout a dive because of such factors as depletion of the prey patch by the predator and escape responses by prey. And the function of the amount of energy intake during a dive cycle is a power function of time spent in foraging area b, or:

$$
g=a \times b^{x}
$$

where parameter a represents a coefficient of conversion of time into actual energy intake. Since the exponent $x$ affects the amount of energy intake per unit time, this exponent can represent quality or prey richness of a prey patch used by the diver. We call this exponent the 'index of patch quality' (IPQ).

We assumed that the diver adjusted diving profiles to maximize the energy intake rate during dive cycle $P$. Then, we can obtain exponent $x$, which maximizes $P$ for a given $t$ and $u$, using Eq. (A1). This exponent $x$ was used as an index of prey richness for the prey patch used by seals in the present study. Since dive time, traveling time (or bottom time) and the relationship between dive time and surface time can be obtained from diving profiles, we can estimate the prey richness of a prey patch at which the diver foraged by calculating the IPQ that maximizes the Eq. (A1) from diving profiles. The parameter a has no contribution to the calculation. See Mori et al. (2002) and Mori \& Boyd (2004) for additional details.

Editorial responsibility: Otto Kinne (Editor-in-Chief), Oldendorf/Luhe, Germany
Submitted: August 12, 2004; Accepted: April 7, 2005

Proofs received from author(s): June 4, 2005 